Background Dutch handball has gained popularity since recent international successes. Downside is the risk of injuries.

Objective To gather information on the prevalence and distribution of injuries in Dutch handball for the development and implementation of targeted preventive measures.

Design Repeated cross-sectional design.

Setting Adolescent and adult handball players active in Dutch leagues of any playing level were invited through social media, club mailings and the website of the Dutch Handball Federation to participate in a monthly online survey.

Participants Handball players (16 years or older) were included. In total 1136 respondents (80\% female) filled in 4171 monthly questionnaires from September 2018 to June 2019.

Risk Factors Outcomes were categorized by sex and playing position.

Main Outcome Measurements New injuries (injury incidence) and number of injured players divided by the total number of respondents (prevalence) per body location. Injury definition: 'the inability to fully participate in handball training and/or matches over the last month due to a problem sustained during handball. The Oslo Sports Trauma Research Centre Questionnaire (OSTRCQ) was used to quantify injury severity.

Results Of 657 new injuries, the knee (21\%), ankle (17\%) and shoulder (10\%) contributed similarly in both sexes and the lower leg predominantly in female players $(10 \%)$. Overall injury prevalence was $43 \%$ (female 46\%, male 34\%). Most prevalent body locations and their mean (standard deviation (sd)) OSTRCQ-scores were the knee (8.8\%; OSTRCQ 61, sd 26), shoulder (4.4\%; OSTRCQ 50, sd 22), ankle (4.0\%; OSTRCQ 55, sd 27) and the lower leg (3.1\%; OSTRCQ 56, sd 26). For all playing positions the knee showed the highest prevalence followed by the shoulder (wings and backs) and/or ankle (backs, pivots and goalies).

Conclusions The high prevalence of knee, ankle and shoulder injuries in both sexes in Dutch handball emphasizes the need for implementation of preventive measures. Preventive training programs already proven successful in handball populations from other countries can be implemented in Dutch handball as well.

\section{INJURY PREVENTION POLICIES IN DUTCH HANDBALL CLUBS}

${ }^{1}$ Maarten Barendrecht, 'Davey Driessen, ${ }^{2}$ Linda van Maanen-Coppens. 'Avans+, Breda, Netherlands; ${ }^{2}$ Dutch Handball Federation, Arnhem, Netherlands

\subsection{6/bjsports-2021-IOC.213}

Background To reduce the number of Handball injuries implementation of preventive measures on all organisational levels is necessary. In Dutch handball clubs, many youth teams are trained/coached by volunteers. Qualified trainers at senior level come and go.

Objective To investigate (barriers and facilitators to) current preventive policies in Dutch handball clubs.

Design Cross-sectional survey.

Setting An online survey was sent to all (371) Dutch handball clubs in February 2018.

Participants Technical committee members/head coaches of sixty-seven clubs (18\% response), covering all competition levels, answered the questionnaire. Units of investigation: Handball clubs: management and trainer level

Main Outcome Measurements Club policies regarding injury prevention and barriers and facilitators for implementation on club level.

Results Of all responding clubs, 20\% had a club policy on injury prevention, in $51 \%$ the choice was up to trainers themselves and the other $29 \%$ had no clear knowledge of a policy on injury prevention. Only 14\% of all clubs had a long-term policy on maintenance of preventive measures. On average $30 \%$ of the active trainers in a club had a trainer's licence of any level. Important barriers for implementation were insufficient knowledge on injury prevention in trainers and/or within the club and lack of implementation competencies within the club. Other barriers were financial, organisational and the high number of volunteers. Insight in the contents and effectiveness of preventive measures by means of an app and/or yearly in-company workshops were suggested strategies to facilitate implementation. Furthermore, external support from the Dutch Handball Federation and support for the implementation process in the club as well as incorporating prevention within athlete development were mentioned.

Conclusions Injury prevention policies seem to be scarcely implemented in Dutch handball clubs although interpretation of these results must take the $18 \%$ response rate into consideration. Externally supported knowledge transfer and implementation management on club level are needed to facilitate the implementation of injury prevention in Dutch handball clubs.

\section{DESCRIPTION OF THE CONTEXT FOR INJURY PREVENTION INTERVENTIONS DEVELOPMENT AND IMPLEMENTATION IN YOUTH BRAZILIAN BASKETBALL: A CROSS-SECTIONAL STUDY}

Luiz Augusto Borges Gomes, Carlos Vicente Andreoli, Ronaldo Alves da Cunha, Helena Santos de Oliveira, Benno Ejnisman, Moises Cohen. Sports and Traumatology Center, Department of Orthopedics and Traumatology, Federal University of São Paulo, São Paulo, Brazil, São Paulo, Brazil

\subsection{6/bjsports-2021-IOC.214}

Background The implementation of injury prevention interventions commonly do not consider the context where injury occurs.

Objective To describe the socioecological context to guide the development and implementation of injury prevention interventions in youth Brazilian basketball (YBB).

Design Cross-sectional study.

Setting YBB teams affiliated to the Basketball Federation of the State of São Paulo. Participants recruitment and data collection occurred during the regular season, between March and September 2018.

Patients (or Participants) 534 athletes and 54 staff members of 35 YBB teams were included in the study. Eligibility criteria included (1) staff members who have graduated in a health care profession and (2) youth athletes with age between 10 and 19 years old.

Interventions (or Assessment of Risk Factors) Participants responded a survey on a regular day of practice or official match. 